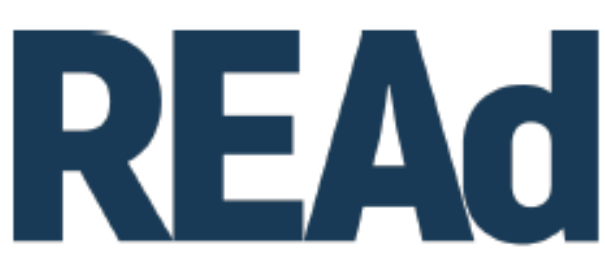

Revista Eletrônica de Administração

\title{
A PRODUÇÃO ACADÊMICA BRASILEIRA SOBRE CORRUPÇÃO: UMA REVISÃO SISTEMÁTICA ${ }^{12}$
}

\author{
Suélem Viana Macedo ${ }^{3}$ \\ Josiel Lopes Valadares ${ }^{4}$
}

http://dx.doi.org/10.1590/1413-2311.319.101302

\begin{abstract}
RESUMO
O presente trabalho teve como objetivo caracterizar a pesquisa acadêmica brasileira sobre corrupção, produzida pelos campos das ciências humanas e das ciências sociais aplicadas. Além disso, buscou compreender como os estudos elaborados por pesquisadores da área da administração têm abordado essa temática. Para tanto, foi delimitado como espaço temporal de análise o período de 2008 a 2017. O delineamento metodológico consistiu em uma revisão sistemática da literatura nacional, que utilizou técnicas de análise de frequência e análise temática do conteúdo do material. Os resultados sugerem que as pesquisas brasileiras que abordaram a corrupção são, em sua maioria: de natureza qualitativa; o foco de investigação é a gestão pública; a abordagem do tema é realizada de uma forma geral, não se referindo a um poder ou esfera de governo específica, o referencial teórico adotado é majoritariamente internacional. O direito é a área que mais tem estudos envolvendo a corrupção, o que se reflete nos debates que são produzidos pela academia. Quanto ao campo da administração, que foi analisado de forma mais específica, os estudos elaborados seguem as mesmas características da produção científica nacional, contudo, o pequeno número de pesquisas desenvolvidas indica que a temática ainda não está totalmente acoplada à agenda dos pesquisadores.
\end{abstract}

Palavras-chave: Corrupção. Produção Acadêmica. Revisão Sistemática. Caracterização. Administração.

\footnotetext{
${ }^{1}$ Recebido em 25/3/2020, aceito em 6/5/2021.

2 Os autores agradecem à Fundação de Amparo à Pesquisa do Estado de Minas Gerais (FAPEMIG) e à Coordenação de Aperfeiçoamento de Pessoal de Nível Superior (CAPES) pelo apoio financeiro à pesquisa).

${ }^{3}$ Universidade Federal de Viçosa - Programa de Pós-Graduação em Adminsitração; https://orcid.org/0000-00017882-557X; susu.viana@hotmail.com.

${ }^{4}$ Universidade Federal de Viçosa - Departamento de Administração e Contabilidade; Viçosa (MG), Brasil; http://orcid.org/0000-0002-2559-9617; adm_josiel@yahoo.com.br. 


\section{THE BRAZILIAN ACADEMIC PRODUCTION ON CORRUPTION: A}

\section{SYSTEMATIC REVIEW}

The present work aimed to characterize the Brazilian academic research on corruption, produced by the fields of human sciences and applied social sciences. In addition, it sought to understand how studies carried out by researchers in the field of administration have addressed this issue. For this purpose, the period from 2008 to 2017 was defined as a temporal space of analysis. The methodological design consisted of a systematic review of the national literature, which used techniques of frequency analysis and thematic analysis of the content of the material. The results suggest that the Brazilian surveys that addressed corruption are mostly: of a qualitative nature; the research focus is public management; the approach of the theme is carried out in a general way, not referring to a specific power or sphere of government, the theoretical framework adopted is mostly international. Law is the area that has the most studies involving corruption, which is reflected in the debates that are produced by the academy. As for the field of administration, which was analyzed in a more specific way, the studies carried out follow the same characteristics of the national scientific production, however, the small number of researches developed indicates that the theme is not yet fully linked to the researchers' agenda.

Keywords: Corruption. Academic Production. Systematic Review. Characterization. Administration.

\section{LA PRODUCCIÓN ACADÉMICA BRASILEÑA SOBRE LA CORRUPCIÓN: UNA REVISIÓN SISTEMÁTICA}

\section{RESUMEN}

El presente trabajo tuvo como objetivo caracterizar la investigación académica brasileña sobre la corrupción, producida por los campos de las ciencias humanas y las ciencias sociales aplicadas. Además, se buscó comprender cómo los estudios llevados a cabo por investigadores en el campo de la administración han abordado este tema. Para ello, se definió como un espacio temporal de análisis el período de 2008 a 2017. El diseño metodológico consistió en una revisión sistemática de la literatura nacional, que utilizó técnicas de análisis de frecuencia y análisis temático del contenido del material. Los resultados sugieren que las encuestas brasileñas que abordaron la corrupción son en su mayoría: de naturaleza cualitativa; el foco de investigación es la gestión pública; el abordaje del tema se realiza de manera general, no refiriéndose a un poder o ámbito de gobierno específico, el marco teórico adoptado es mayoritariamente internacional. Derecho es el área que tiene más estudios sobre corrupción, lo que se refleja en los debates que se producen desde la academia. En cuanto al campo de la administración, el cual fue analizado de manera más específica, los estudios desarrollados siguen las mismas características de la producción científica nacional, sin embargo, el pequeño número de investigaciones desarrolladas indica que el tema aún no está completamente vinculado a la agenda de los investigadores.

Palabras clave: Corrupción. Producción Académica. Revisión Sistemática. Caracterización. Administración. 


\section{INTRODUÇÃO}

A corrupção, nas suas mais diversas espécies, está presente na história da humanidade desde a antiguidade (KLITGAARD, 1998; JAIN, 2001; MARTINS, 2008). Em termos conceituais, trata-se de um fenômeno que está em constante mudança. Deste modo, qualquer definição conferida à corrupção será limitada, pois dependerá do contexto em que se pretende defini-la (SOUZA; SILVA; GOMES, 2019). Nesta pesquisa, para delimitar o objeto de estudo, entende-se a corrupção como o abuso de poder público em favor de interesse privado, visando ganhos ilícitos (ROSE-ACKERMAN, 1999; ANDERSSON, 2017).

Assim, parte-se do pressuposto de que a corrupção é um fenômeno multidimensional, pois pode ocorrer em organizações de qualquer natureza, manifestando-se tanto no setor público quanto no privado (KLITGGARD, 1998). Em virtude disso, o seu combate se tornou uma preocupação para os regimes democráticos (AVRITZER; FILGUEIRAS, 2011) e, particularmente, um desafio para a administração pública brasileira (BUENO; BRELÀZ; SALINAS, 2016). Conforme Marani et al. (2018), as preocupações experimentadas na prática diária dos governos servem de catalizadores para pesquisas que serão desenvolvidas no âmbito científico. Os autores apontam, ainda, que a corrupção, um dos maiores inimigos das organizações, tem reiterado sua habilidade para desafiar a pesquisa científica a compreendê-la.

Nesse contexto, visando conhecer e caracterizar a produção acadêmica brasileira na área da administração pública, Sacramento e Pinho (2009) realizaram um estudo exploratório sobre a temática da corrupção, no período compreendido entre 1997 e 2008. Após a análise, os autores apontaram que esse tipo de pesquisa tinha espaço para produção no campo analisado; contudo, a corrupção ainda era pouco investigada, quase de forma irrelevante em termos quantitativos.

Em um estudo recente, Marani et al. (2018) traçaram um panorama sobre as discussões acumuladas em torno da corrupção. Os autores apontaram que as pesquisas brasileiras sobre corrupção são introdutórias, conceituais e dizem respeito, em sua maioria, à percepção, suas causas, efeitos, controle e modo de apresentação pela mídia. Além disso, os trabalhos são encontrados, com maior frequência, em ensaios e livros. Os autores argumentam, ainda, que parte significativa da produção brasileira sobre corrupção se constitui a partir de um quadro referencial teórico estrangeiro (MARANI et al., 2018).

Souza, Silva e Gomes (2019) também buscaram compreender como a temática da corrupção na administração pública vem sendo debatida na literatura internacional. No referido estudo, discutiu-se a evolução do conceito de corrupção, suas causas, consequências, formas de medi-la empiricamente, prevenção e combate. Os autores constataram que a literatura sobre 
corrupção vem crescendo dentro do campo da administração pública em todo o mundo, sendo que estudos comparativos e relacionados ao nível local têm sido a tendência (SOUZA; SILVA; GOMES, 2019).

Pinho e Sacramento (2018) acrescentam, ainda, que nos últimos anos ou décadas a corrupção, que não configurava como tão relevante pela maioria dos estudiosos brasileiros, adquiriu maior centralidade na academia, em razão dos sucessivos escândalos que têm marcado a vida política do país. Segundo os autores, em geral, esses estudos apresentam e constatam a existência de corrupção, contudo, não têm a preocupação de qualificá-la (PINHO; SACRAMENTO, 2018).

Tais trabalhos, contudo, não apresentaram uma caracterização geral dos estudos encontrados, como as áreas acadêmicas que têm pesquisado o assunto, o tipo de abordagem adotada pelos pesquisadores brasileiros, o âmbito e as esferas de poder e de governo investigadas. Além disso, não levaram em consideração as dissertações e teses que abordaram esse assunto. No caso do estudo de Sacramento e Pinho (2009), apesar da pesquisa ter se concentrado apenas na produção acadêmica brasileira, ela abarcou somente trabalhos publicados pela área da administração pública, desconsiderando, portando, os demais campos do conhecimento que também abordam a questão da corrupção em suas produções.

Assim, considerando a corrupção como um fenômeno multidisciplinar e multidimensional, que pode ocorrer em organizações de qualquer natureza (KLITGGARD, 1998) e que tem se manifestado de maneira recorrente na administração pública brasileira, o presente estudo buscou responder à seguinte questão: como se caracteriza a pesquisa acadêmica brasileira sobre corrupção produzida pelos campos das ciências humanas e das ciências sociais aplicadas?

Desse modo, o objetivo geral da pesquisa consistiu em caracterizar a pesquisa acadêmica brasileira sobre corrupção produzida pelos campos das ciências humanas e das ciências sociais aplicadas. Além disso, buscou compreender, de forma mais específica, como os estudos elaborados por pesquisadores da área da administração têm abordado essa temática, delimitando como espaço temporal de investigação o período de 2008 a 2017. Esse recorte de dez anos foi definido visando compreender como a corrupção vem sendo analisada em pesquisas mais recentes. Segundo Pinho e Sacramento (2018), nos últimos anos, a corrupção assumiu um novo patamar, por isso, o discurso acadêmico que antes era genérico, passou a ter mais foco se referindo a objetos concretos e não mais intangíveis.

Para tanto, as análises empreendidas foram realizadas em duas fases. Na primeira etapa, os resultados da pesquisa foram apresentados a partir da identificação de artigos, dissertações 
e teses que tiveram como objeto de estudo a corrupção, buscados no Portal de Periódicos da Coordenação de Aperfeiçoamento de Pessoal de Nível Superior (Capes) e no Banco de Teses e Dissertações da Capes. Foram escolhidas essas duas bases porque elas comtemplam estudos brasileiros de diversas áreas, incluindo os campos das ciências humanas e das ciências sociais aplicadas, havendo possibilidade, inclusive, de filtrar os trabalhos que se inserem, especificamente, nessas duas áreas. Quanto à análise de trabalhos sobre corrupção produzidos por pesquisadores da área específica da administração, para complementar os resultados, também foram identificados artigos publicados na Scientific Periodicals Electronic Library (SPELL) e nos anais dos eventos promovidos pela Associação Nacional dos Programas de PósGraduação em Administração (ANPAD).

Este estudo, diferentemente dos trabalhos anteriores, apresenta uma perspectiva mais ampla da produção acadêmica brasileira sobre corrupção, a partir da identificação do foco de investigação e da abordagem realizada pelos pesquisadores, do referencial teórico adotado e dos assuntos discutidos nas pesquisas. Além disso, a escolha por fazer uma análise restrita da área da administração, após apresentar um panorama geral dos campos das ciências humanas e das ciências sociais aplicadas, se deu em razão da notoriedade que a corrupção na gestão pública tem ganhado no contexto brasileiro. Assim como Sacramento e Pinho (2009) fizeram para o campo da administração pública, buscou-se identificar como essa problemática tem sido pesquisada e discutida, de uma forma geral, por acadêmicos da administração. Como a corrupção envolve atores do setor público e privado, optou-se por não restringir a análise apenas à área da administração pública.

Conhecer a produção acadêmica brasileira sobre a corrupção pode ajudar a identificar questões que merecem receber uma maior atenção da academia nacional ou que precisam ser trabalhadas sob outras perspectivas, favorecendo a formação de uma agenda de estudos mais consistente, bem como o aperfeiçoamento de pesquisas e investigações futuras. Em termos de contribuições, a realização da revisão sistemática da literatura sobre corrupção avança na construção do conhecimento sobre esse tema, permitindo a identificação de quais áreas têm se interessado mais por essa temática e em que medida o fato desse fenômeno estar tão presente nas discussões políticas e sociais atuais tem influenciado na pesquisa científica. 


\section{PROCEDIMENTOS METODOLÓGICOS}

Como forma de atingir o objetivo proposto, este artigo, de caráter qualitativo e descritivo, utilizou a revisão sistemática como estratégia de pesquisa. A revisão sistemática é definida "como uma síntese de estudos primários que contém objetivos, materiais e métodos claramente explicitados e que foi conduzida de acordo com uma metodologia clara e reprodutível" (GREENHALGH, 1997, p. 672). Baseia-se, deste modo, em um método que pode ser replicável e transparente, por meio do emprego de critérios explícitos para seleção dos artigos da revisão (BOTELHO; DE ALMEIDA CUNHA; MACEDO, 2011; COOK; MULROW; HAYNES, 1997), permitindo uma visão geral sobre um tópico que é reconhecidamente amplo (PETERSON; PEARCE; FERGUSON; LANGFORD, 2017). Esse processo de mapeamento e estruturação de informações, segundo Martins (2021), visa evidenciar o atual estado da arte, bem como demonstrar a existência de lacunas e oportunidades de estudos sobre determinado tema, contribuindo para a elaboração de trabalhos futuros.

Considerando essa perspectiva, a pesquisa foi dividida em duas fases. Inicialmente foram feitas buscas sobre o tema no Portal de Periódicos Capes e no Banco de Teses e Dissertações da Capes. Em um segundo momento, para complementar os resultados encontrados na primeira fase, também foram realizadas buscas na biblioteca eletrônica SPELL e nos anais dos eventos promovidos pela ANPAD, a fim caracterizar os estudos realizados por pesquisadores da área da administração, em particular. Considerou-se que essas são as fontes de dados que reúnem os trabalhos científicos mais significativos da produção acadêmica nacional, nas quais esperou-se localizar estudos em que a corrupção constituísse ou, no mínimo, fizesse parte do objeto principal da pesquisa.

Operacionalmente, a coleta de dados buscou encontrar nas bases analisadas artigos teóricos e/ou empíricos que tratassem sobre a corrupção, sem restrições com relação ao contexto em que ela foi abordada. Por essa razão, os critérios de busca foram definidos da seguinte forma: conter no título ou no resumo ou em suas palavras-chave algum termo com o prefixo "corrup", não havendo restrições quanto ao idioma dos trabalhos. Também foi delimitado um corte temporal de dez anos (janeiro de 2008 a dezembro de 2017).

No Portal de Periódicos Capes foi realizada uma busca avançada por assunto, na qual os termos foram procurados no título ou no assunto dos artigos acadêmicos indexados. Tal pesquisa resultou em 256 estudos. Já no Banco de Teses e Dissertações da Capes aplicou-se um filtro para as áreas das ciências sociais aplicadas e das ciências humanas, remontando uma totalidade de 547 dissertações e 135 teses. Na SPELL, delimitou-se como área de conhecimento 
os campos da administração, administração pública, contabilidade e economia, resultando em um total de 67 artigos. Nos anais dos eventos promovidos pela ANPAD, a referida busca revelou um total de 29 artigos.

Destaca-se, por fim, que as visitas ao Banco de Teses e Dissertações da Capes, à SPELL e aos anais dos eventos promovidos pela ANPAD foram realizadas no período compreendido entre 30 de novembro de 2017 a 24 de abril de 2018. Já no Portal de Periódicos Capes, a busca por artigos foi efetuada entre os dias 11 e 15 de março de 2019.

Feita essa seleção e organizados os estudos encontrados em um repositório, realizou-se a análise individual dos artigos, teses e dissertações, por meio da leitura do título, resumo e de suas palavras-chave. Quando necessário foi efetuada, ainda, uma leitura da metodologia dos estudos. Ficou constatado que a presença dos termos pesquisados apenas no resumo do trabalho, na maioria das pesquisas, significava o reconhecimento da corrupção como um problema. Porém, quando o termo se fazia presente também no título, verificou-se que a corrupção assumia uma maior centralidade no trabalho. Nessa etapa, foram excluídas as pesquisas que, apesar de conterem o termo, não abordavam a corrupção como objeto de estudo ou que não estavam relacionadas ao tema propriamente dito.

Além disso, também foram removidos os artigos em duplicidade, os que não foram desenvolvidos com a participação de autores brasileiros e os que foram publicados em revistas que não têm cunho acadêmico. No que se refere às teses e às dissertações, foram retirados da análise os trabalhos em que se identificou apenas o título e os que, embora contivessem o resumo, não foi possível ter acesso ao seu inteiro teor para confirmar como foi desenvolvida a pesquisa. Após essa filtragem, os dados dos estudos selecionados foram tabulados em uma planilha eletrônica de Excel. Assim, a análise continuou com 146 artigos e 225 teses e dissertações. Dessa forma, de um total de 1.034 estudos, restaram apenas 371 documentos, distribuídos conforme descrito no Quadro 1.

Quadro 1. Quantidade de artigos selecionados em cada base de dados

\begin{tabular}{|c|c|c|}
\hline Base de Dados & Tipo de trabalho & $\begin{array}{c}\text { Quantidade de pesquisas } \\
\text { selecionadas }\end{array}$ \\
\hline Portal de Periódicos Capes & Artigo & 113 \\
\hline SPELL & Artigo & 15 \\
\hline Anais dos eventos promovidos pela ANPAD & Artigo & 18 \\
\hline \multirow{2}{*}{ Banco de Teses e Dissertações da Capes } & Dissertação & 171 \\
\cline { 2 - 3 } & Tese & 54 \\
\hline
\end{tabular}

Fonte: Resultados da pesquisa.

Selecionados os estudos, foi realizada uma análise da frequência geral dos trabalhos encontrados no Portal de Periódicos Capes e no Banco de Teses e Dissertações da Capes, a fim 
de se identificar a quantidade anual de trabalhos relacionados à corrupção, bem como as áreas que mais pesquisaram o tema em dissertações e teses, as universidades que desenvolveram a temática da corrupção em seus programas e as revistas que mais publicaram artigos sobre o assunto.

Após identificar esses elementos, os trabalhos selecionados foram agrupados nas seguintes categorias: classificação do estudo quanto à natureza (teórico ou teórico-empírico); opção metodológica (qualitativa, quantitativa ou ambas); direção do foco investigativo (âmbito público ou privado; poder executivo, legislativo ou judiciário; nível federal, estadual, municipal, nacional ou transnacional), bem como a caracterização do referencial teórico dos artigos selecionados no Portal de Periódicos Capes por meio da identificação dos autores mais citados. Essa última análise não abarcou as dissertações e teses, pois não foi possível ter acesso ao conteúdo das referências bibliográficas de todos os estudos.

Embora um dos objetivos da revisão sistemática também seja apontar a evolução das teorias e dos aportes teóricos dados ao tema (VOSGERAU; ROMANOWSKI, 2014), como o corpus de análise do trabalho abarcou mais de trezentos estudos, apontar estas características demandaria a leitura da integralidade das pesquisas, o que metodologicamente não estava no escopo do artigo. Porém, parte-se do pressuposto de que a análise dos referentes mais utilizados e dos principais assuntos discutidos permite refletir sobre os debates teóricos que vêm sendo construídos em torno da corrupção pela academia brasileira.

Por fim, para identificar quais questões costumam estar relacionadas à corrupção na pesquisa científica dos campos das ciências sociais aplicadas e das ciências humanas, a análise explorou ainda, com o auxílio do software Iramuteq, os temas que mais aparecem nos títulos e palavras-chave dos trabalhos selecionados. Destacou-se, também, em um tópico próprio, como a produção acadêmica sobre corrupção, relacionada à área de administração no Brasil, está caracterizada. Para tanto, além dos trabalhos encontrados nas plataformas da Capes, essa análise contemplou, ainda, os artigos publicados na SPELL e nos anais dos eventos promovidos pela ANPAD. Os resultados estão descritos na seção seguinte.

\section{ANÁLISE E DISCUSSÃO DOS RESULTADOS}

\subsection{ANÁLISE DESCRITIVA DOS RESULTADOS DAS BUSCAS DE ARTIGOS, TESES E DISSERTAÇÕES}

Considerando a amostra da pesquisa, quanto ao volume da produção acadêmica encontrada no Portal de Periódicos Capes e no Banco de Teses e Dissertações da Capes, é 
possível identificar um crescente aumento ao longo dos anos, como se observa no Gráfico 1. Nota-se, contudo, que a partir de 2014 é que houve um aumento considerável na quantidade de dissertações e teses, passando de 16 em 2013 para 39 em 2014. Quanto à publicação de artigos em revistas, é possível notar um salto em 2015, que dobrou a quantidade em relação à 2014 . Com relação à queda considerável no número de dissertações e teses no ano de 2017, que diminuiu de 46 trabalhos para 16, acredita-se que nem todos os trabalhos defendidos no referido ano foram indexados no banco de dados da CAPES, no momento em que foram realizadas as buscas.

Gráfico 1. Evolução da produção acadêmica brasileira sobre a corrupção

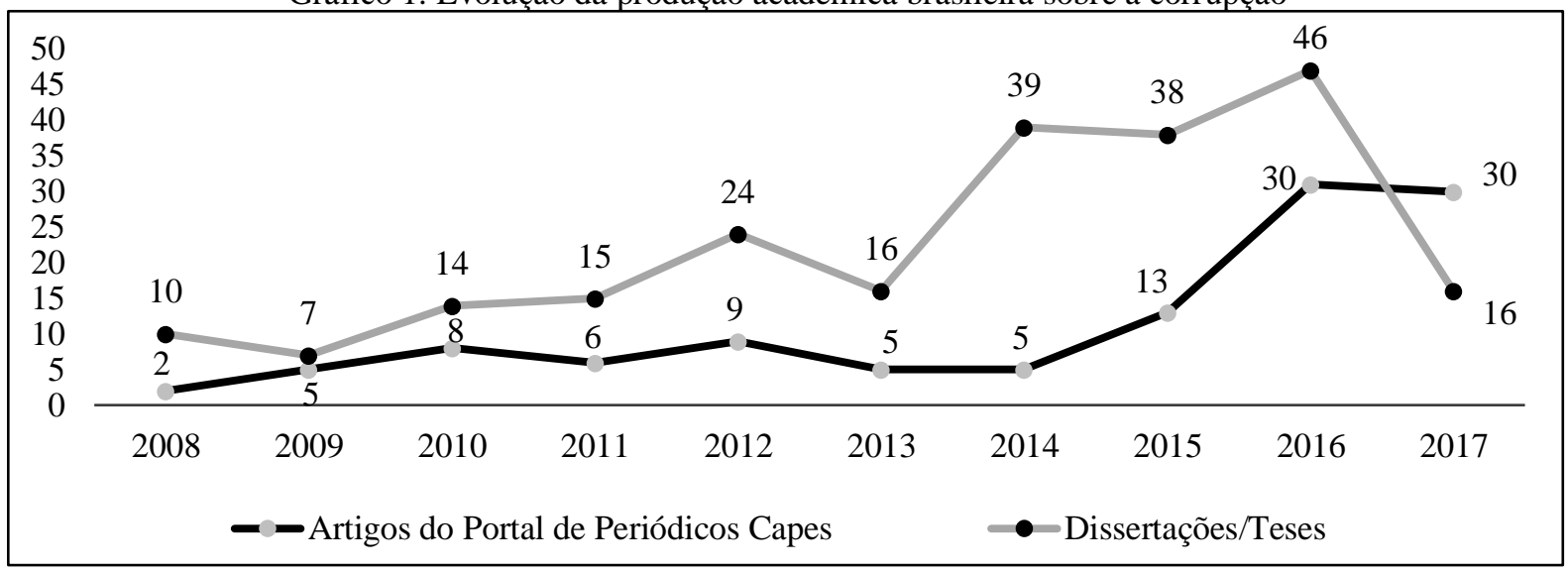

Fonte: Resultados da pesquisa.

No que diz respeito às áreas que têm pesquisado a temática da corrupção, quanto às dissertações e teses, os cursos relacionados aos campos do direito, da administração privada/pública, da economia, da ciência política, das ciências sociais, da comunicação da e contabilidade foram os que mais se destacaram. De um total de 225 trabalhos analisados, 94 estudos, o que corresponde a $42 \%$, dizem respeito a pesquisas produzidas por acadêmicos vinculados a programas de pós-graduação em alguma área do direito, tais como ciências jurídicas, criminais, direito constitucional, político e econômico, direitos humanos, negocial, coletivo e social.

Nesse cenário, o campo da administração conta com apenas $13 \%$ dos trabalhos, nos quais incluem-se pesquisas vinculadas ao setor público e privado. Pesquisas na área da economia apresentam esse mesmo percentual de trabalhos (13\%), seguida da ciência política com $11 \%$ e das ciências sociais e da comunicação com 3,5\% cada uma. Os cursos de contabilidade e filosofia contam um percentual de 3\% cada e as demais áreas, nas quais estão incluídas a sociologia, história, relações internacionais e psicologia, representam um total de $8 \%$ dos estudos. 
Tais resultados indicam que a corrupção é um fenômeno multidisciplinar. Entretanto, embora a sua presença no âmbito da gestão pública seja recorrente, ela ainda é pouco abordada pelos pesquisadores dos cursos stricto sensu em administração. Quando comparamos com as demais áreas, especialmente o campo do direito, que foi responsável por aproximadamente metade das dissertações e teses encontradas, a pouca atenção dada pelos pesquisadores da administração a esse assunto fica ainda mais evidente.

Essa análise comparativa do quantitativo de estudos demonstrou, portanto, que algumas áreas, como é o caso do direito, têm se dedicado mais a analisar o assunto, em termos de número de pesquisas realizadas. Desse modo, embora a corrupção seja um problema que tem causado prejuízos aos cofres da gestão pública brasileira, essa problemática ainda é quantitativamente pouco abordada por pesquisadores que atuam em áreas voltadas para a análise da administração pública, o que, consequentemente, influencia nos tipos de discussões que têm sido promovidas sobre a corrupção pela academia.

Quanto às instituições de ensino, todas as dissertações e teses selecionadas foram elaboradas por sessenta e cinco universidades e faculdades do país. Sendo que, em apenas cinco foram desenvolvidas mais de dez pesquisas por programas de pós-graduação de diferentes áreas do conhecimento, conforme ilustrado no Quadro 2:

Quadro 2. Instituições de ensino que tiveram mais pesquisas sobre a corrupção

\begin{tabular}{|c|c|c|}
\hline \multirow{2}{*}{ Universidades } & Áreas dos Programas de Pós-Graduação & $\begin{array}{c}\mathbf{N}^{\mathbf{o}} \text {. de pesquisas } \\
\text { em cada área }\end{array}$ \\
\hline \multirow{3}{*}{$\begin{array}{c}\text { Universidade de } \\
\text { Brasília }\end{array}$} & Relações Internacionais, Contabilidade e Ciência Política & 3 cada \\
\cline { 2 - 3 } & Direito e Economia & 2 cada \\
\cline { 2 - 3 } & Sociologia, Psicologia, Comunicação e Administração & 1 cada \\
\hline \multirow{3}{*}{$\begin{array}{c}\text { Pontifícia Universidade } \\
\text { Católica de São Paulo }\end{array}$} & Direito & 11 \\
\cline { 2 - 3 } & Psicologia & 1 cada \\
\hline \multirow{2}{*}{$\begin{array}{c}\text { Universidade Federal } \\
\text { de Pernambuco }\end{array}$} & Sociais & 6 cada \\
\cline { 2 - 3 } & Ciência Política e Economia & 2 \\
\hline \multirow{2}{*}{$\begin{array}{c}\text { Universidade de Santa } \\
\text { Cruz do Sul }\end{array}$} & Direito & 1 \\
\hline \multirow{2}{*}{$\begin{array}{c}\text { Universidade de São } \\
\text { Paulo }\end{array}$} & História & 14 \\
\cline { 2 - 3 } & Direito & 6 \\
\cline { 2 - 3 } & Controladoria e Contabilidade, Economia e História & 1 cada \\
\hline
\end{tabular}

Fonte: Resultados da pesquisa.

Esse resultado evidencia que a produção acadêmica por pesquisadores vinculados a programas de pós-graduação de diferentes cursos está pulverizada em instituições de ensino do 
país. Entretanto, apenas cinco delas concentram aproximadamente um terço (33\%) de todas as dissertações e teses elaboradas sobre o tema, destacando-se com um maior número de trabalhos os programas de pós-graduação em Direito.

Com relação à frequência de artigos publicados em oitenta e um periódicos diferentes, a relação das revistas que mais publicaram artigos que contaram com a participação de pesquisadores brasileiros encontra-se no Quadro 3. Todas as demais sessenta e duas revistas que não foram listadas publicaram um artigo cada relacionado à corrupção.

Quadro 3. Listagem das revistas que mais publicaram artigos tratando da corrupção

\begin{tabular}{|c|c|c|c|}
\hline Revista & Total & Revista & Total \\
\hline Opinião Pública & 6 & \multirow{2}{*}{ Conpedi Law Review } & \multirow{2}{*}{2} \\
\hline Revista Controle & 4 & & \\
\hline $\begin{array}{l}\text { Revista de Direito Administrativo e } \\
\text { Gestão Pública }\end{array}$ & 4 & Media \& Jornalismo & 2 \\
\hline Revista Direito GV & 4 & Revista Científica Hermes & 2 \\
\hline Revista Espaço Acadêmico & 4 & Revista de Administração Pública & 2 \\
\hline Em Tese & 3 & Revista de Direito Setorial e Regulatório & 2 \\
\hline $\begin{array}{l}\text { Estudos Econômicos } \\
\text { (São Paulo) }\end{array}$ & 3 & $\begin{array}{l}\text { Revista de Processo, Jurisdição e Efetividade da } \\
\text { Justiça }\end{array}$ & 2 \\
\hline $\begin{array}{l}\text { Revista de Administração } \\
\text { Contemporânea }\end{array}$ & 3 & $\begin{array}{l}\text { Sinergia: Revista do Instituto de Ciências } \\
\text { Econômicas, Administrativas e Contábeis }\end{array}$ & 2 \\
\hline Meridiano 47 & 2 & Dados: Revista de Ciências Sociais & 2 \\
\hline $\begin{array}{c}\text { Cadernos do Programa de Pós- } \\
\text { Graduação em Direito - } \\
\text { PPGDIR/UFRGS }\end{array}$ & 2 & Direito e Desenvolvimento & 2 \\
\hline
\end{tabular}

Fonte: Resultados da pesquisa.

De modo geral, a partir dos resultados iniciais encontrados, considera-se que, embora a corrupção não seja um fenômeno novo no contexto brasileiro, nos últimos dez anos a pesquisa acadêmica sobre esse assunto aumentou consideravelmente. Nesse mesmo período, uma gama de atos corruptos praticados ao longo dos anos por integrantes do setor público também passou a ser amplamente divulgada aos cidadãos pelos meios de comunicação.

Como se observa no Gráfico 1, de 2014 em diante as publicações envolvendo a temática da corrupção mais que dobraram de quantidade, correspondendo exatamente ao período em que a Operação Lava-Jato, maior operação policial e judicial de combate à corrupção na administração pública brasileira, foi deflagrada pela Polícia Federal brasileira. A partir de tais resultados, pressupõe-se que os movimentos sociais contra a corrupção que surgiram nesses últimos anos, a consequente crise política e financeira enfrentada pelo país e a investigação e prisão de políticos e empresários por atos de corrupção contribuíram para que o tema conquistasse espaço nas discussões sociais, como ponderado por Pinho e Sacramento (2018), 
emergindo na produção acadêmica brasileira como um tema que também parece despertar maior interesse, ainda que de forma pequena frente à problemática que ele envolve.

Destaca-se, contudo, que nos casos em que há prática de corrupção, diferentemente de outros tipos de crimes, o corrupto e o corruptor buscam a todo custo minimizar a possibilidade de descoberta de seus atos, o que dificulta a apuração desse fenômeno e a sua consequente mensuração. Em virtude disso, pressupõe-se que o fato de os estudos sobre a corrupção terem aumentado nos últimos anos está ligado à publicidade que as práticas corruptas têm ganhado nos meios de comunicação.

No estudo, portanto, foi possível constatar que ao mesmo tempo em que a corrupção se tornou mais divulgada pelos meios de comunicação, ela também ganhou maior espaço nas agendas de pesquisa dos campos das ciências humanas e das ciências sociais aplicadas. Quanto ao ponto, vale destacar o papel e a influência que a mídia exerce sobre os discursos sociais e políticos e sobre a academia. Assim como a corrupção tornou-se um desafio para a administração pública brasileira (BUENO; BRELÀZ; SALINAS, 2016), principalmente, em razão de seus efeitos, ela também tem despertado maior interesse dos pesquisadores.

\subsection{ANÁLISE TEMÁTICA DOS ESTUDOS ENCONTRADOS}

O principal objetivo desta subseção é apresentar os resultados referentes à caracterização dos trabalhos encontrados no Portal de Periódicos Capes e no Banco de Teses e Dissertações da Capes, de acordo com as categorias definidas e relacionadas na seção em que os procedimentos metodológicos foram apresentados.

\subsubsection{Conhecendo os estudos quanto à natureza e abordagem adotadas}

A identificação das estratégias de investigação utilizada nos trabalhos de pesquisa indica o tipo de conhecimento que está sendo produzido em determinada área, permitindo visualizar, assim, se o trabalho é especulativo, empírico, se existem modelos sendo produzidos e aplicados e, até mesmo, se existe a intenção de produção e desenvolvimento de teorias (LOIOLA; BASTOS, 2003). Nesse sentido, os trabalhos selecionados para este estudo foram classificados em teórico ou teórico-empírico, de acordo com a manifestação exposta no trabalho. Quando ela não estava explícita, foi verificada na metodologia do trabalho a existência ou não da análise empírica. Os resultados são apresentados no Gráfico 2. 
Gráfico 2. Natureza dos trabalhos

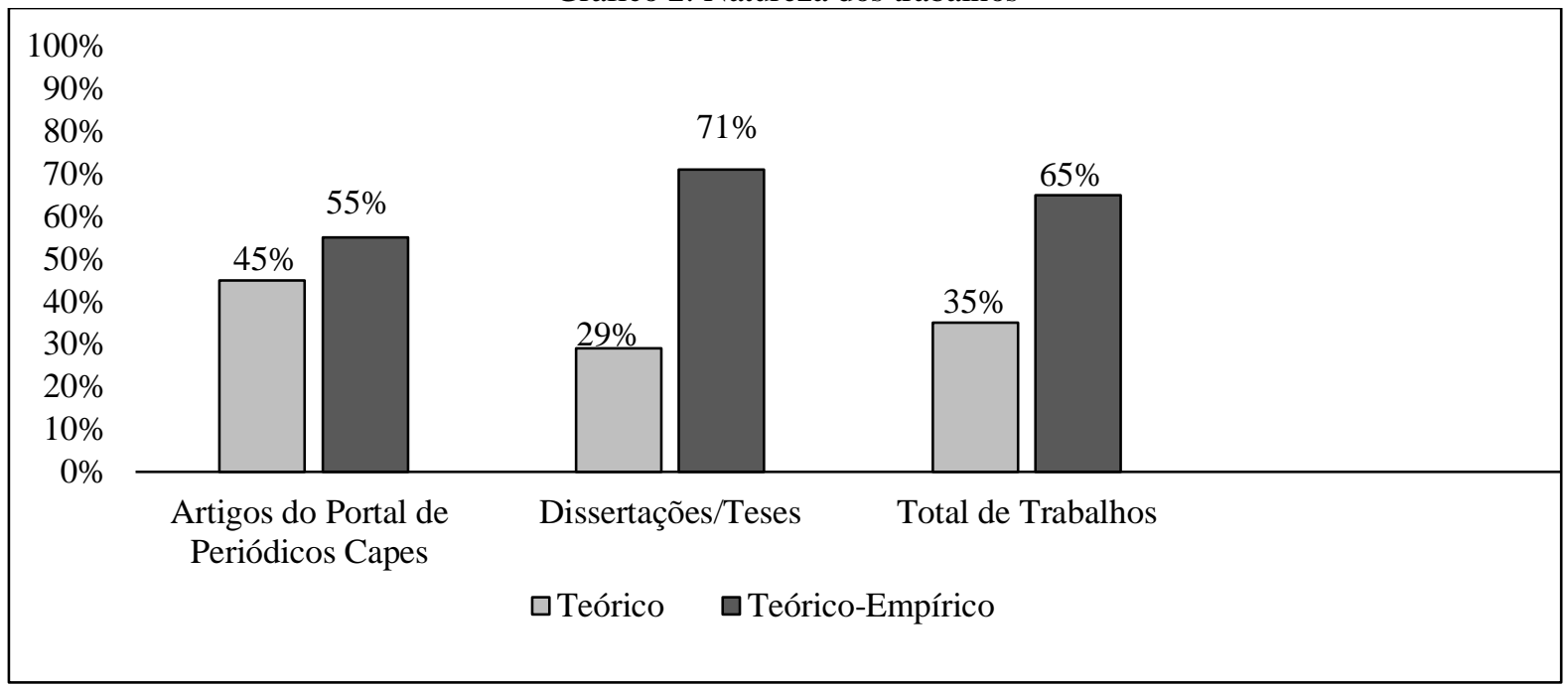

Fonte: Resultados da pesquisa.

Apesar dessa análise abarcar outras áreas do conhecimento, os resultados encontrados, assim como os de Sacramento e Pinho (2009), continuam indicando que os pesquisadores possuem uma inclinação para o desenvolvimento de trabalhos sobre corrupção com base empírica. A partir disso, pressupõe-se que, devido ao fato de a corrupção ser um fenômeno recorrente no contexto brasileiro e muitas vezes difícil de se identificar, os pesquisadores têm buscado entender, explicar e medir como ela se manifesta na prática, a partir da análise de dados empíricos. Verificou-se, ademais, que os trabalhos teóricos, em percentual menor, também possuem espaço na produção acadêmica brasileira. Tais pesquisas, de modo geral, são elaboradas na forma de ensaios teóricos, que procuram discutir a corrupção a partir de uma perspectiva mais reflexiva.

No que se refere ao tipo de abordagem utilizada, buscou-se identificar a opção metodológica escolhida, a partir da verificação de trabalhos qualitativos, quantitativos ou que empregassem essas duas abordagens ao mesmo tempo. Na produção acadêmica de artigos, embora este estudo tenha abarcado outras áreas além da administração pública, os resultados, assim como os de Sacramento e Pinho (2009), continuam apresentando a predominância de estudos qualitativos em detrimento dos quantitativos, como disposto no Gráfico 3. 
Gráfico 3. Tipo de abordagem

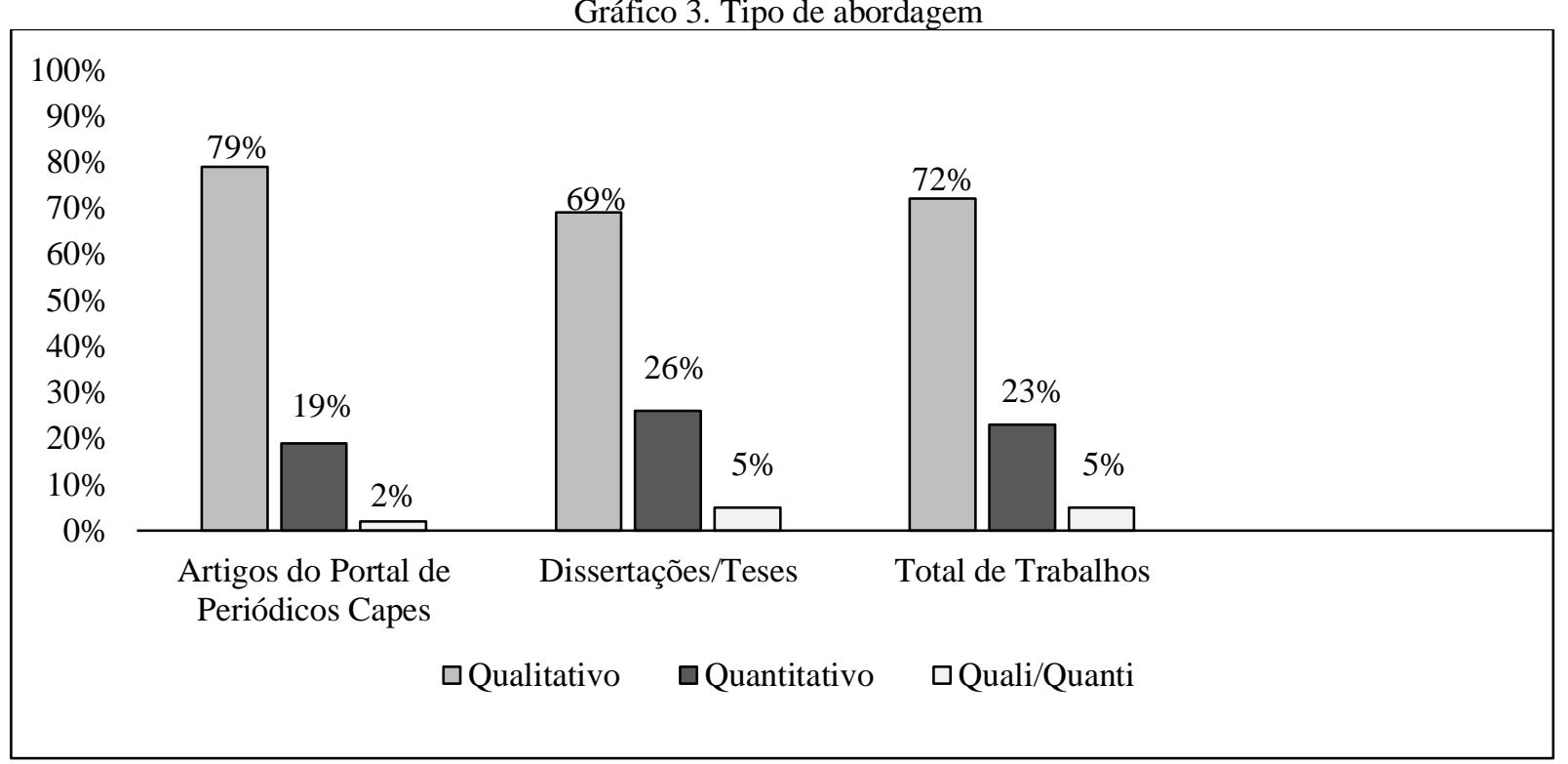

Fonte: Resultados da pesquisa.

Tais resultados sugerem que a busca por estudos das áreas das ciências humanas e das ciências sociais aplicadas e, ainda, como uma parcela considerável das pesquisas pertencem ao campo do direito, das ciências políticas e sociais e da comunicação, isso pode ter contribuído para que a opção metodológica dos autores por estudos qualitativos tenha prevalecido em detrimento dos quantitativos. Observou-se, deste modo, que as pesquisas sobre corrupção desenvolvidas pela produção acadêmica brasileira utilizam, de um modo geral, opções metodológicas diferentes, embora a abordagem qualitativa tenha sido adotada de forma mais reiterada.

Conforme Souza, Silva e Gomes (2019), as tentativas de medir a corrupção na administração pública encontram diversos desafios metodológicos, sobretudo, porque é difícil de se medir e compreender algo que não pode ser facilmente observado de forma direta. Ademais, há dificuldades em se conseguir relatórios oficiais e dados públicos. Supõe-se, dessa forma, que essa seja uma justificativa para o número reduzido de trabalhos que utilizam a opção metodológica quantitativa, pois dependem da obtenção de dados que, diante da complexidade a qual a corrupção está envolta, podem ser difíceis de serem conseguidos.

Assim, apesar da importância dos métodos quantitativos, admite-se, também, que o emprego de técnicas qualitativas pode ajudar a entender certas questões que a abordagem quantitativa não consegue abarcar. Sendo assim, a triangulação dos dados, por meio da (c) (1) 8 
combinação de diferentes métodos de coleta e análise, pode ser uma alternativa para se compreender com maior profundidade a temática da corrupção.

\subsubsection{Conhecendo o foco da investigação}

A corrupção pode possuir significados diferentes dependendo do contexto que está sendo analisada. Na política, por exemplo, ela pode ser entendida como ganhos ilícitos associados ao poder político ou mesmo à manutenção desse poder (KLITGGARD, 1998). Em um âmbito econômico, essas vantagens podem ser financeiras. A corrupção também pode ocorrer no âmbito privado, ou seja, nas relações particulares mantidas entre as pessoas e as organizações. Já na seara da administração pública, na maioria das vezes, a corrupção está relacionada ao uso de cargos públicos para ganhos pessoais e/ou econômicos (ROSEACKERMAN, 1999). Assim, considerando as diversas abordagens que a corrupção ganha, dependendo do contexto que ela está inserida, este estudo buscou conhecer a direção do olhar da produção acadêmica.

Para tanto, buscou-se identificar em qual âmbito a prática da corrupção tem chamado mais a atenção dos pesquisadores, se público, privado ou se a discussão tem englobado tal fenômeno de forma geral. Em seguida, averiguou-se se a análise tinha como foco algum poder da república em particular ou se a corrupção era tratada de forma mais genérica, sem abordar um poder em específico. Finalmente, completando a análise, o último passo foi conhecer em qual esfera de governo a produção acadêmica brasileira sobre corrupção tem se concentrado e, não sendo esse o caso, se os trabalhos são de contexto nacional ou transnacional. Os resultados estão expostos no Gráfico 4.

Gráfico 4. Âmbito, Poder e Esferas de governo investigadas 


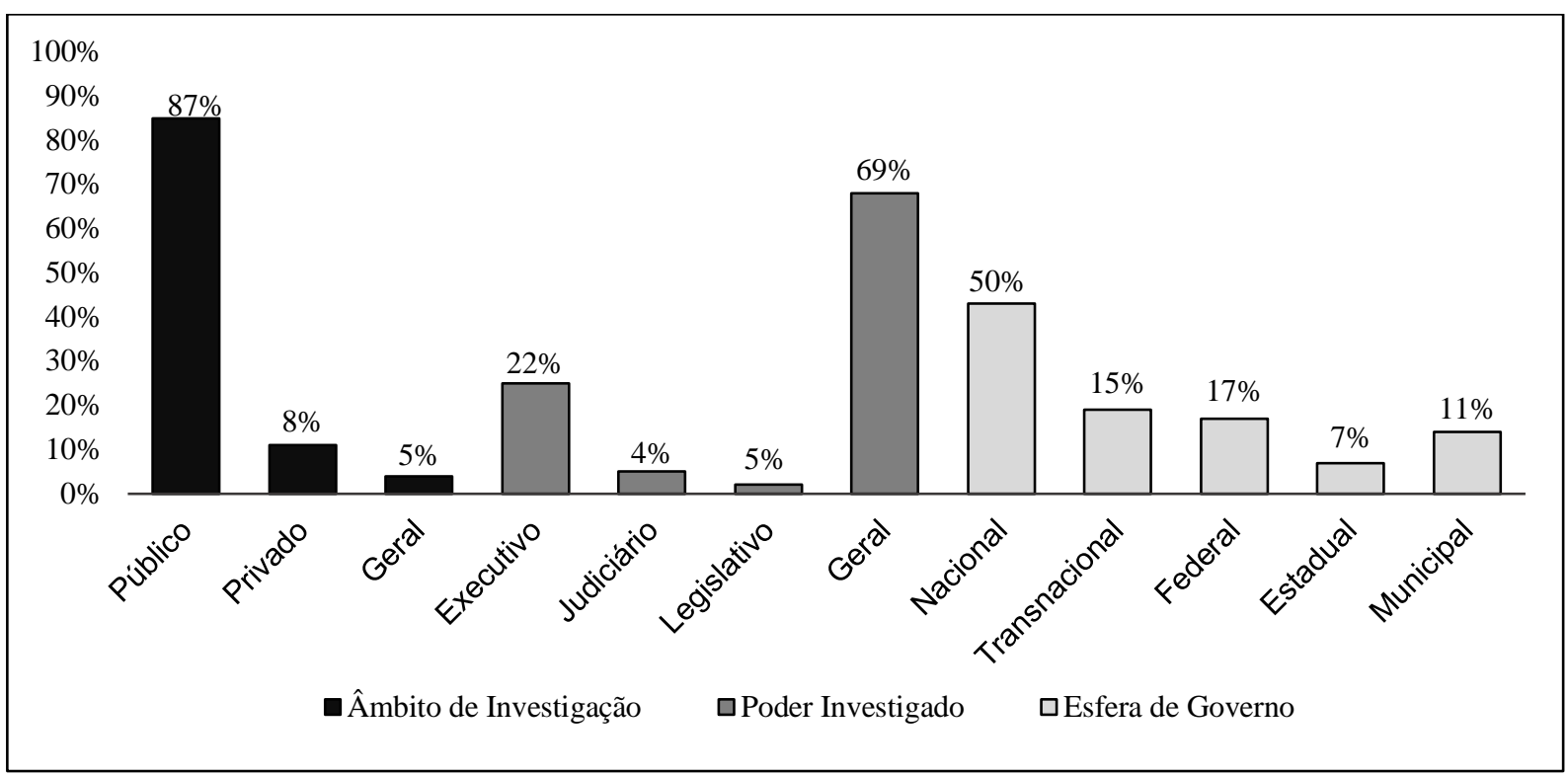

Fonte: Resultados da pesquisa.

Conforme se observa, ficou constatado que grande parte dos trabalhos, mais precisamente $87 \%$, estuda a prática da corrupção no âmbito público. A leitura que se faz dessa informação é que atos relacionados à corrupção praticados na arena pública interessam mais aos pesquisadores do que os que ocorrem na iniciativa privada. Quanto ao setor privado, as pesquisas têm como foco maior a prática de atos corruptos dentro de organizações, por conseguinte, pouco se investiga a respeito dos comportamentos corruptos cotidianos dos indivíduos.

Com relação ao poder investigado, em $69 \%$ das pesquisas analisadas verificou-se que não havia foco em um poder específico, isto é, a análise dos pesquisadores tratou a corrupção de forma mais geral, como um fenômeno que está presente nas relações privadas e públicas, ou não adentrou em questões relacionadas aos poderes do estado, como nos casos em que o âmbito de investigação foi o setor privado. Quanto a esse ponto, identificou-se pesquisas que trabalharam a questão da corrupção como uma prática que ocorre no país como um todo, não sendo exclusivo de um poder específico, ou que abarcaram mais de um poder em sua análise. Do restante, $22 \%$ analisaram situações envolvendo especificamente o poder executivo, $4 \%$ o poder judiciário e apenas $5 \%$ o legislativo.

Considera-se, dessa forma, que a maioria dos trabalhos selecionados tratam a corrupção no setor público como um fenômeno presente em todas as esferas de poder, embora o judiciário e o legislativo ainda sejam pouco discutidos. Aliás, uma parcela considerável dos trabalhos, principalmente aqueles produzidos no campo do direito, abordou a corrupção aliada às previsões legais que punem essa prática. Trabalhos específicos sobre as recentes operações policiais que investigam a corrupção na administração pública e as suas repercussões na mídia 
também foram verificados. No que diz respeito aos estudos que tiveram como foco o judiciário, nenhum dos trabalhos investigou a ocorrência da corrupção nesse poder em específico. O objeto de análise de tais pesquisas foi a atuação do judiciário, especialmente o Supremo Tribunal Federal, no combate à corrupção no Brasil, abordando, ainda, questões relacionadas aos procedimentos legais e julgamento de processos.

Além disso, ficou evidenciado que, da mesma forma que a corrupção vem sendo abordada de modo mais geral, não se referindo a um poder em particular, mas ao contexto nacional como um todo, os estudos também não têm dado tanto foco a uma esfera de governo específica, o que representa $50 \%$ das pesquisas. Além da corrupção ser abordada como um fenômeno presente na cultura brasileira, $15 \%$ dos estudos discutiram a sua ocorrência em outros países, analisando o contexto transnacional. Com relação às esferas de governo propriamente ditas, o âmbito federal é o que mais tem sido estudado, com um percentual de $17 \%$. Com um índice um pouco menor (11\%), os municípios também têm sido abordados em trabalhos acadêmicos. Por outro lado, a esfera estadual brasileira tem recebido pouca atenção dos pesquisadores, representando apenas $7 \%$ da produção acadêmica.

Foi possível verificar, dessa forma, que a temática da corrupção tem ganhado cada vez espaço na produção acadêmica brasileira, em especial, a ocorrência desse fenômeno no setor público. Por ser um problema multidimensional, presente de diferentes maneiras em diversos setores, a maioria dos trabalhos abordam a corrupção de um modo mais geral, sem discutir o contexto particular em que ela está inserida. Todavia, entender como esse fenômeno ocorre em situações e setores específicos pode ajudar a compreender melhor as suas causas e até mesmo a melhor forma de combatê-lo. Por esta razão, a pesquisa nacional sobre corrupção ainda carece de diversificação quanto ao seu foco investigativo, seja com relação ao poder ou à esfera de governo investigada, no sentido de abordar áreas que ainda são pouco estudadas, como é caso do legislativo e do judiciário, bem como dos governos estaduais.

\subsubsection{Conhecendo o referencial teórico}

Buscou-se, ainda, conhecer a bibliografia utilizada em cada pesquisa a fim de identificar as fontes mais utilizadas. Conforme Caldas e Tinoco (2004), uma das funções das citações bibliográficas é oferecer indicações quanto à contribuição de autores percursores para o trabalho, representando o reconhecimento formal de débito intelectual com os autores que trataram o tema anteriormente. Destaca-se, contudo, que a referida busca se concentrou apenas nas referências bibliográficas dos trabalhos, independentemente de se tratar especificamente da 
corrupção. Além disso, foram listados apenas os nomes dos autores mais citados nos estudos selecionados e não os trabalhos propriamente ditos. Para evitar uma tabela muito longa foram destacados apenas os autores que tiveram dez ou mais citações. O resultado está evidenciado no Quadro 4.

\begin{tabular}{|c|c|c|c|}
\hline \multicolumn{4}{|c|}{ Quadro 4. Autores mais citados } \\
\hline Autor & $\begin{array}{c}\mathrm{N}^{0} \text {. de } \\
\text { Citações }\end{array}$ & Autor & $\begin{array}{c}N^{0} . \text { de } \\
\text { Citações }\end{array}$ \\
\hline Rose-Ackerman, S. & 31 & Tanzi, V. & 12 \\
\hline Filgueiras, F. & 25 & Carvalho, J. M. & 11 \\
\hline Habermas, J. & 16 & Ehrlich, I. & 11 \\
\hline Becker, G. S. & 15 & Ferraz, C. \& Finan F. & 11 \\
\hline Kant, I. & 15 & Klitgaard, R. & 11 \\
\hline O`Donnell, G. & 15 & Shleifer, A. \& Vishny, R. & 11 \\
\hline Rousseau, J. & 15 & Weber, M. & 11 \\
\hline Mauro, P. & 14 & Kauffmann, D. & 10 \\
\hline
\end{tabular}

Fonte. Resultados da pesquisa.

Assim como observado nas pesquisas de Sacramento e Pinho (2009) e Marani et al. (2018), a pulverização de trabalhos indica que os pesquisadores utilizaram diferentes bibliografias. Verifica-se, ademais, o predomínio de autores estrangeiros, pois dos dezesseis autores que mais foram citados, apenas dois são nacionais (Fernando Filgueiras e José Murilo de Carvalho), o que demonstra uma menor utilização de estudos nacionais nas pesquisas sobre corrupção. Em virtude disso, apesar da utilização da literatura internacional que trata sobre o tema ser importante, é necessário, também, que seja aperfeiçoada a construção de um pensamento brasileiro.

Deve-se ressaltar, contudo, que a citação frequente dos estudos nacionais indica que o caminho para a elaboração de perspectivas críticas e teóricas sobre a corrupção no contexto brasileiro já está começando a ser traçado. As pesquisas realizadas por Filgueiras trazem diferentes contribuições aos estudos analisados. O autor possui trabalhos que vão desde a discussão de correntes de pensamento e marcos teóricos da corrupção, até a definição do fenômeno e apresentação de suas formas e práticas (FILGUEIRAS, 2008a, 2008b, 2009). Isso sugere que ainda há uma preocupação teórica dos trabalhos mais recentes em discutir o conceito da corrupção. Já os estudos de José Murilo de Carvalho tratam, em geral, da relação do brasileiro com a lei e com as práticas de corrupção ao longo da história (CARVALHO, 2008). A utilização desse autor como referente é um indicativo de que os pesquisadores vêm tentando compreender empiricamente as raízes da corrupção no Brasil e as questões culturais e políticas que estão por trás desse fenômeno.

Como a referência mais utilizada pela literatura analisada são os trabalhos de RoseAckerman, tal fato sugere que estudos nacionais sobre a corrupção também têm se preocupado 
em compreender as suas causas e efeitos, a partir de variáveis econômicas, como defendido por Rose-Ackerman (1999), Becker (1968), Ehrlich (1974), Mauro (1995), Tanzi (1998), Shleifer e Vishny (1993) e Kauffmann et al. (2002). A utilização de autores como O`Donnell (1998), Ferraz e Finan (2008) e Klitgaard (1998) evidencia, ainda, a atenção que os trabalhos analisados têm oferecido à questão do controle e combate à corrupção. A discussão filosófica sobre a corrupção também está presente nos estudos mais recentes, principalmente, a partir das perspectivas teóricas de Jürgen Habermas, Immanuel Kant, Jean Jacques Rousseau.

Essa análise dos principais referentes utilizados sugere que diferentes aportes teóricos têm sido apresentados ao tema corrupção. No mesmo sentido do que foi apontado por Souza, Silva e Gomes (2019), que analisaram a literatura internacional, no contexto brasileiro a literatura acadêmica também tem se atendado para questões relacionadas ao conceito da corrupção, suas causas, efeitos, controle e combate. Essa preocupação acaba refletindo nos principais temas que são discutidos pela literatura mais recente.

\subsection{PRINCIPAIS ASSUNTOS DISCUTIDOS}

Por ser um fenômeno presente em diferentes contextos, a análise da corrupção pela produção acadêmica pode estar relacionada a diversos assuntos que ajudam a explicá-la e a compreender um pouco da sua complexidade. Com o software Iramuteq gerou-se uma representação gráfica da frequência dos cinquenta termos mais citados nos títulos e nas palavras-chaves dos estudos selecionados no Portal de Periódicos Capes e no Banco de Teses e Dissertações da Capes. A nuvem de palavras gerada, constante na Figura 1, evidencia o grau de importância de um termo, considerando sua frequência na base de dados. Logo, quanto maior for a palavra, mais frequente e relevante ela é nas fontes de informações. Ressalta-se que essa técnica considera os elementos em forma de palavras simples. 
Figura 1. Nuvem de Palavras

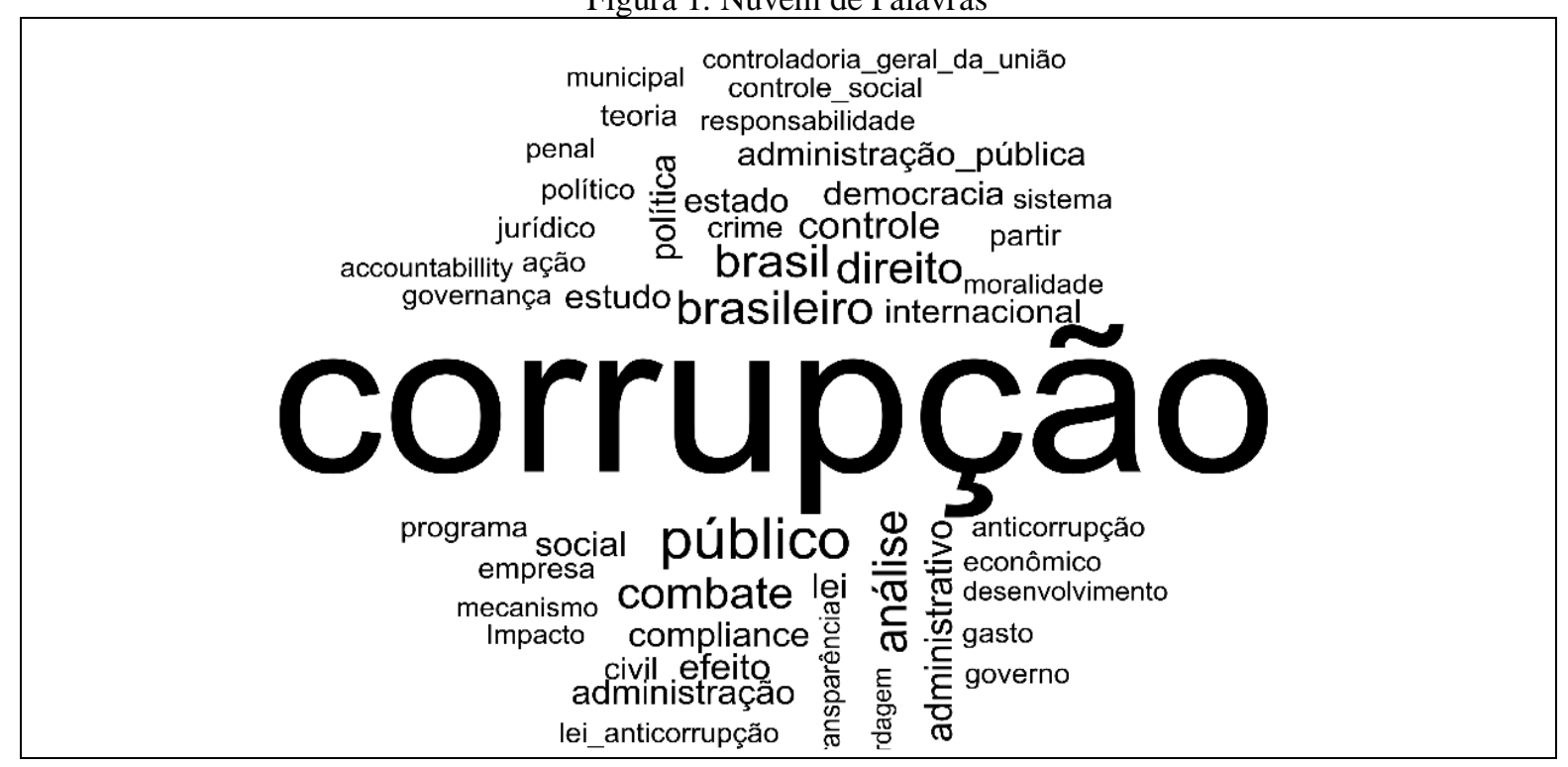

Fonte: Elaborado pelos autores por meio do software Iramuteq.

Como o termo de busca dos estudos foi a palavra corrupção, consequentemente, foi ela que ganhou maior destaque dentro do conjunto de textos analisados. As palavras "administração pública", "público", "pública", "brasil" e "brasileiro" corroboram os resultados de que a maioria das pesquisas estudam a corrupção no setor público dentro do contexto brasileiro, embora o termo "internacional" e "empresa" também tenham aparecido com frequência, mas com menor realce. A palavras "controle", "combate", "efeito" e "impacto" também evidenciam que as pesquisas brasileiras têm seguido a agenda de pesquisa internacional sobre essa temática, cujo foco inclui o estudo da prevenção, controle, consequências e medição da corrupção (SOUZA; SILVA; GOMES, 2019).

No Brasil, de modo geral, um aparato de leis visa coibir e punir a prática de atos corruptos. Observa-se, deste modo, que o fato da lei receber um grande destaque nesse contexto, faz com que ela, juntamente com os mecanismos burocráticos de controle, receba uma maior atenção não só do cidadão e da administração pública, mas também dos próprios pesquisadores. Como há um número considerável de trabalhos na área do direito, principalmente teses e dissertações, termos como "lei", "lei anticorrupção", "jurídico", "civil", "pena” e "crime” foram recorrentes nos textos analisados. Aliás, observou-se uma inclinação da pesquisa em estudar a Lei $n^{\circ}$. 12. 846/2013, conhecida como Lei Anticorrupção, que prevê a responsabilização objetiva, no âmbito civil e administrativo, de empresas que praticam atos lesivos contra a administração pública nacional ou estrangeira.

Ademais, o fato de o poder executivo ser tratado com maior ênfase também pode ser verificado a partir da Figura 1. Foram utilizadas com frequência as palavras "municipal", 
"política", "Estado", "governo", "governança" e "Controladoria Geral da União". Conforme mencionado anteriormente, as discussões acadêmicas brasileiras sobre a corrupção ainda giram muito ao redor do executivo em detrimento dos demais poderes. Acredita-se que estender as análises para as três esferas de poder pode ajudar a compreender com maior profundidade as razões da corrupção estar tão presente no contexto brasileiro.

Alguns termos que não tiveram tanto destaque na nuvem de palavras, mas que também merecem atenção quando se fala em corrupção, foram "econômico", "desenvolvimento", "gasto", "eficiência", "responsabilidade" e "moralidade". Cada um deles contribui da sua maneira para a compreensão da corrupção, inclusive, para a definição do seu conceito. Por fim, no que se refere a atuação da sociedade frente a esse fenômeno, questões como "controle social", "democracia", "accountabillity" e "transparência” também apareceram com frequência nos títulos e palavras-chave dos textos analisados. Nesse ponto, vale destacar a importância de inserir nos debates relacionados à corrupção a discussão sobre o papel dos cidadãos e o dever da administração pública de se mostrar mais aberta e transparente.

\subsection{UM BREVE PANORAMA DOS ESTUDOS SOBRE CORRUPÇÃO EM ADMINISTRAÇÃO}

Como foi possível verificar na seção anterior, a pesquisa sobre corrupção tem espaço na produção acadêmica na área da administração e, em termos quantitativos, ela também tem crescido. De um total de 113 artigos encontrados no Portal de Periódicos Capes, apenas 19 foram publicados por autores pertencentes ao campo da administração. Quanto às teses e dissertações, do total de 225 trabalhos, apenas 30 foram produzidas por programas de mestrado e doutorado.

Complementando esses resultados, também foram encontrados 15 artigos publicados na SPELL tratando sobre a corrupção e 18 nos anais de eventos produzidos pela ANPAD. No que diz respeito à evolução da produção acadêmica sobre corrupção na área da administração, conforme delimitado no Gráfico 5, em 2016, foi possível verificar um aumento maior na quantidade anual de estudos. 


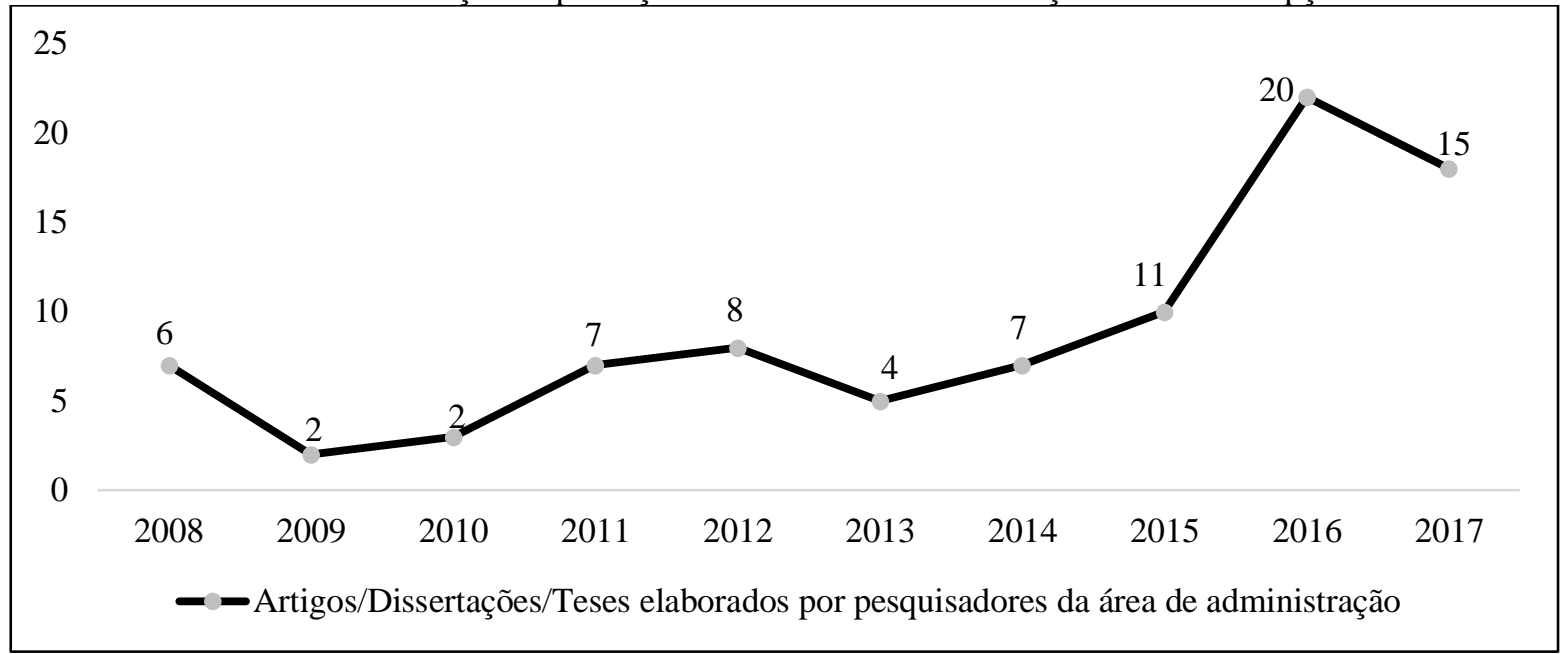

Fonte: Resultados da pesquisa.

Quanto às instituições de ensino que tiveram dissertações e teses desenvolvidas por acadêmicos da área de administração, dezesseis universidades e faculdades se destacaram. Destas, a Fundação Getúlio Vargas/SP, com sete estudos, a Universidade FUMEC, com cinco, a Universidade Federal de Santa Catarina, com três, e a Universidade Federal do Rio Grande do Norte e Fundação Getúlio Vargas/RJ, com dois cada uma; foram as únicas instituições que tiveram mais de uma pesquisa realizada. Tal resultado indica que aproximadamente dois terços das dissertações e teses elaboradas por programas de pós-graduação em administração, pública e privada, foram desenvolvidas em apenas cinco instituições de ensino superior do país.

Já das vinte e sete revistas que publicaram artigos tratando sobre a corrupção, elaborados por autores pertencentes à área da administração, as que mais tiveram publicações foram a Revista de Administração Contemporânea (4), a Revista de Contabilidade e Organizações (3), a Revista do Serviço Público (3), a Revista Pensamento \& Realidade (2), a Brazilian Business Review (2) e a Revista de Administração (2).

A caracterização da natureza dos trabalhos, o tipo de abordagem e o foco da investigação quanto ao âmbito, ao poder e à esfera de governo encontram-se no Gráfico 6. 


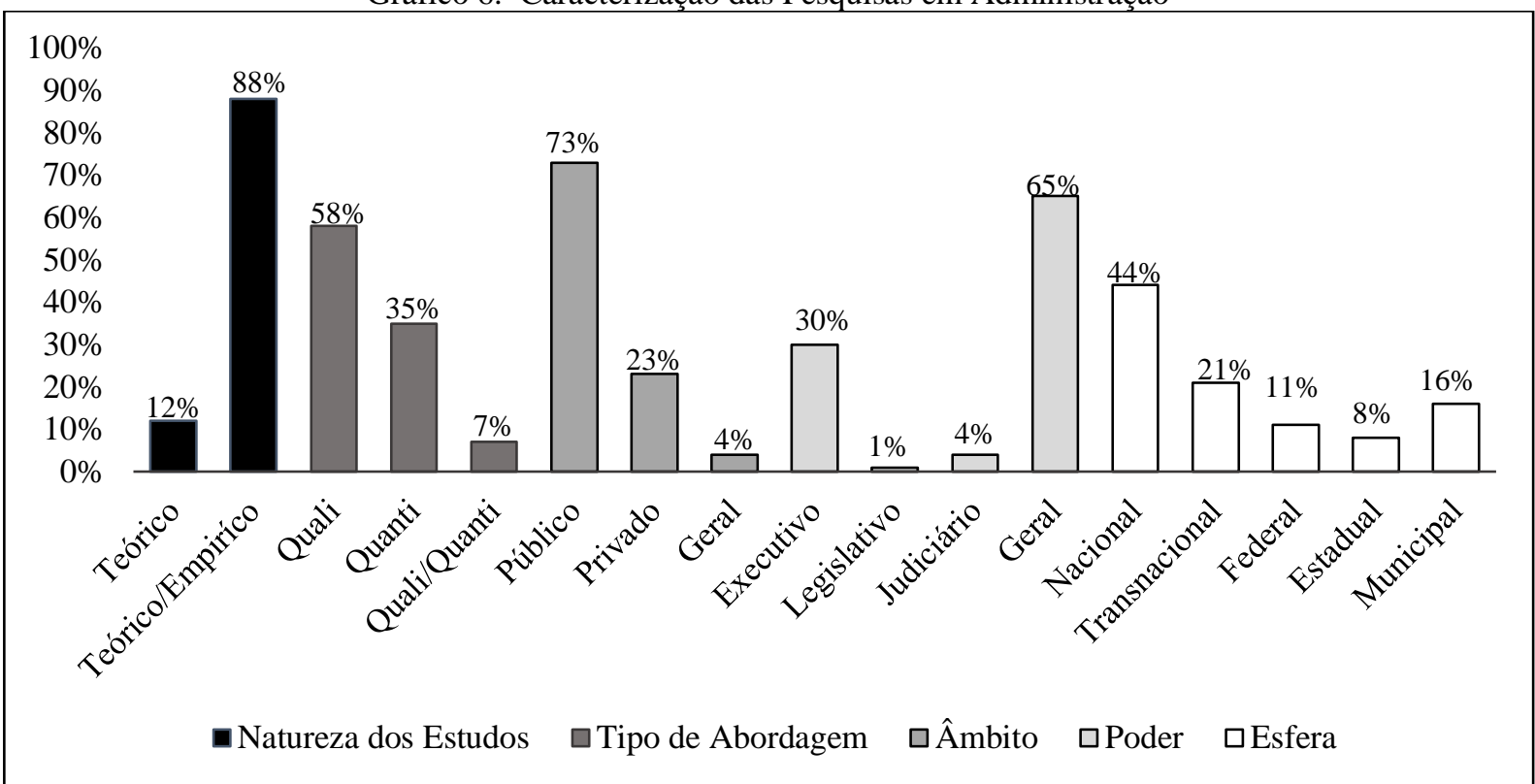

Fonte: Resultados da pesquisa.

Assim como foi observado nos estudos em geral, na área da administração também predominam trabalhos teórico-empíricos $(88 \%)$, de caráter qualitativo $(58 \%)$, cujo foco da investigação é a corrupção no setor público (73\%). Quanto ao poder e à esfera de governo, a abordagem, de igual modo, foi realizada de forma generalizada (65\%), com maior ênfase ao âmbito nacional, sem delimitar uma esfera de governo em específico. De todos os poderes da república, o executivo brasileiro constitui-se o mais visado pelos estudos da administração que objetivam investigar a corrupção.

Esses resultados, assim como os de Sacramento e Pinho (2009), evidenciam como a produção acadêmica brasileira em administração não diversificou seu foco nos últimos anos, pois o legislativo e o judiciário continuam recebendo uma pequena atenção dos pesquisadores, apesar da literatura enfatizar que a corrupção também está presente nesses poderes. Revelam, ademais, que embora a corrupção esteja presente no setor privado e público, os pesquisadores têm buscado compreendê-la, de forma geral, independente do contexto em que está inserida.

Destaca-se, ainda, que a produção acadêmica na área da administração tem se preocupado em discutir a corrupção em nível internacional, abarcando diferentes países, e também no âmbito local, a partir de análises das esferas públicas federal, estadual e municipal. Segundo Abrucio (2007), a esfera municipal, em comparação com os demais níveis de governo, é um ambiente permeado por baixas capacidades gerenciais e administrativas, o que, por conseguinte pode abrir mais espaços e incentivos para a corrupção florescer (ARANHA, 2015). Daí a importância de se desenvolver estudos que busquem compreender a corrupção de um 
modo mais abrangente, mas que também investiguem como as especificidades dos contextos analisados podem contribuir ou inibir a sua ocorrência.

No que se refere aos autores mais referenciados pelos artigos desenvolvidos por pesquisadores da área de administração, no Quadro 5 são listados os nomes que tiveram dez ou mais citações.

Quadro 5. Autores mais citados por estudos desenvolvidos na área da administração

\begin{tabular}{|l|l|l|l|}
\hline Autor & $\begin{array}{l}\mathbf{N}^{\mathbf{o}} \mathbf{d e} \\
\text { Citações }\end{array}$ & Autor & $\begin{array}{l}\mathbf{N}^{\mathbf{o}} \text { de } \\
\text { Citações }\end{array}$ \\
\hline Filgueiras, F. & 32 & Mauro, P. & 12 \\
\hline Rose-Ackerman, S. & 26 & Kaufman, D. & 12 \\
\hline Pinho, J. A. G & 19 & Abramo, C. W. & 11 \\
\hline Avritzer, L. & 16 & Shleifer, A. \& Vishny, R. & 11 \\
\hline Klitgaard, R. & 14 & Sacramento, A. R. S. & 11 \\
\hline O`Donnell, G. & 14 & Speck, B. & 10 \\
\hline
\end{tabular}

Fonte. Resultados da pesquisa.

Entre os doze autores mais citados nos trabalhos publicados por pesquisadores da área de administração, estão cinco brasileiros, sendo eles Fernando Filgueiras, José Antonio Gomes de Pinho, Leonardo Avritzer, Claudio Weber Abramo e Ana Rita Silva Sacramento. A última autora mencionada, entretanto, é a única que possui formação específica na área de administração, visto que os demais nomes citados transitam, mais especificamente, no campo da ciência política. Isso pode ser uma consequência do baixo número de estudos já produzidos pelos pesquisadores da administração (MARANI et al., 2018; SACRAMENTO; PINHO, 2009) e/ou da pouca influência que essas discussões ofereceram para os debates posteriores.

Em termos de referencial teórico, as pesquisas produzidas área da administração têm se baseado na literatura brasileira com mais frequência que os trabalhos elaborados, de forma geral, pelos campos das ciências sociais aplicadas e das ciências humanas. Contudo, os autores citados são vinculados, em sua maioria, a outras áreas do conhecimento. Os principais assuntos discutidos por essa literatura e que refletem as perspectivas teóricas utilizadas pela academia envolvem debates que abordam a corrupção no Brasil a partir de diferentes facetas (AVRITZER, 2008), assim como o seu conceito e controle (FILGUEIRAS, 2008, 2009; SACRAMENTO, 2010), a sua ligação com a cultura patrimonialista presente na gestão pública nacional (PINHO, 1998) e a dificuldade em mensurá-la (SPECK, 2000; ABRAMO, 2005). Vale destacar, contudo, que embora no campo da administração os trabalhos façam maior menção a estudos nacionais, a abordagem da corrupção a partir de variáveis econômicas também é realizada com regularidade pelas pesquisas produzidas pelo campo da administração. 
Considera-se, dessa forma, que os estudos elaborados por pesquisadores da área da administração seguem as mesmas características da produção científica nacional, com exceção da análise do referencial teórico, que teve maior quantidade de autores brasileiros entre as bibliografias mais citadas. Conforme Marani et al. (2018) existe uma estreita relação entre o modo como a pesquisa em administração pública se organiza na atualidade e a agenda governamental. Entretanto, quando o assunto é corrupção, considerando o número de trabalhos encontrados, os estudos sobre como esse fenômeno tem se desenvolvido nos levam a crer que a temática ainda não está totalmente acoplada à agenda do governo e à agenda dos pesquisadores que integram o campo da administração.

\section{CONSIDERAÇÕES FINAIS}

Tendo em conta a relevância que a corrupção tem ganhado no contexto anual, nos últimos dez anos, principalmente a partir de 2014, observamos que os debates sobre esse assunto aumentaram no Brasil, não só no âmbito das discussões políticas e sociais, mas também se estendendo à pesquisa científica. As evidências indicam que essa maior centralidade que o tema ganhou deve-se aos aos sucessivos escândalos que têm marcado o âmbito político do país. Contudo, diante da complexidade desse fenômeno, os resultados continuam apontando que ainda há muito o que avançar, sobretudo, no que se refere aos poderes e às esferas de governo que são investigadas.

Embora a corrupção seja um fenômeno difícil de se compreender e que é recorrente no contexto brasileiro, isso não foi suficiente para que a pesquisa brasileira dedicasse uma maior atenção para um assunto que ainda desafia o Estado como um todo. Coincidência ou não, no ano em que a Operação Lava-Jato começou a ser a divulgada pela mídia é que se observou um maior crescimento das publicações de artigos e de elaboração de teses e dissertações tratando da corrupção. Deste modo, um ponto a ser considerado quando se analisa a produção acadêmica nacional sobre corrupção, diz respeito ao papel que a mídia exerce na determinação da agenda de pesquisas desenvolvidas pelos campos das ciências sociais aplicadas e das ciências humanas.

Partindo dos resultados apresentados neste trabalho, observa-se, ainda, que o direito é a área que mais se interessa pela temática da corrupção. Por conseguinte, isso reflete nos debates que são produzidos pela academia, muitas vezes voltados apenas para a discussão de lei, quando o problema, devido à sua obscuridade, é muito mais profundo. Não se pode negar, porém, que a análise da corrupção continua saindo de uma esfera mais abstrata para uma mais concreta, considerando a predominância de trabalhos teórico-empíricos. Ampliar o âmbito das pesquisas, 
assim como apresentado no trabalho de Sacramento e Pinho (2009), também é uma questão que precisa ser aprimorada. A corrupção não é um obstáculo presente apenas no executivo, entender como ela está disseminada nos diversos setores e poderes públicos e, também, nas relações privadas, pode ajudar a compreender melhor como combatê-la.

Como contribuições práticas, a pesquisa traça um panorama geral da produção acadêmica em torno da corrupção relativa aos últimos dez anos, complementando os estudos anteriores. As pesquisas sobre esse tema ainda são recentes, a robustez e a solidez necessárias devem ser atingidas com o avanço nos estudos. Especificamente quanto ao campo da administração, que foi destacado em um tópico próprio deste estudo, os resultados apresentados evidenciam o quanto a agenda de pesquisas desenvolvidas por essa área precisa avançar, principalmente no que se refere ao direcionamento do seu olhar. Os poderes legislativo e judiciário, embora envolvidos em escândalos tanto quanto o executivo, não atraem tanto a atenção da produção científica. Deste modo, ao caracterizar a produção científica nacional, este estudo também oferece aos pesquisadores nacionais um ponto de partida para que a elaboração de discussões sobre a corrupção no meio científico seja aprofundada.

Em termos de contribuições teóricas, como este estudo identificou questões que merecem receber uma maior atenção da academia nacional ou que precisam ser trabalhadas sob outras perspectivas, a pesquisa colabora para a formação de uma agenda mais sólida de estudos sobre corrupção. Além disso, permite a identificação das áreas do conhecimento que mais têm se interessado por essa temática, dos debates que têm sido produzidos, colaborando para o aperfeiçoamento das metodologias e técnicas utilizadas, bem como dos temas e objetos estudados quando se trata da corrupção.

Vale ressaltar, ainda, que devido ao grande número de trabalhos que integraram a pesquisa, trezentos e setenta e um no total, não foram objeto específico de análise as teorias utilizadas na elaboração das pesquisas que integraram este estudo. Porém, partindo dos principais referentes e assuntos discutidos é possível inferir parte dos aportes teóricos que vêm sendo oferecidos ao tema: a corrupção no setor público é a mais abordada pelos trabalhos, o que denota que ela pode gerar mais "incômodo" à academia em relação à corrupção que ocorre no setor privado; embora o referencial utilizado seja em sua maioria internacional, o caminho para a elaboração de perspectivas críticas e teóricas que evidenciem a construção de um pensamento nacional sobre a corrupção já está sendo delineado, por meio da citação de autores de nacionais; há uma preocupação da literatura em compreender as causas, a mensuração e os efeitos da corrupção, sendo que a utilização de variáveis econômicas tem contribuído de forma mais contundente para essa análise; o controle e combate da corrupção associados às ideias de 
democracia, accountabillity, controle social, governança e transparência são assuntos que também têm sido abordados pela academia.

Ao classificar os estudos quanto à natureza, à opção metodológica, à direção do foco investigativo e ao referencial teórico mais utilizado nos artigos elaborados, esta pesquisa não só traça um mapa do estado da arte da produção acadêmica brasileira sobre corrupção, mas, também, lista os pontos que merecem maior atenção da academia, constituindo possíveis agendas de pesquisa, tais como: (1) elaboração de trabalhos que também analisem a corrupção presente nas relações privadas; (2) ampliação das opções metodológicas, por meio de estudos práticos e de abordagem quantitativa; (3) direcionamento do lócus de análise para poderes e esferas de governo específicas; (4) construção de estudos que insiram referências bibliográficas nacionais, aperfeiçoando a construção de um pensamento brasileiro sobre a corrupção.

Para o campo da administração, em particular, considerando as lacunas encontradas, sugere-se a elaboração de estudos que contemplem a análise da corrupção nos poderes legislativo e judiciário e, também, no âmbito federal e estadual. Além disso, são bem-vindas pesquisas que busquem formas de se identificar e medir a corrupção no contexto brasileiro, bem como alternativas que contribuam para o seu combate e prevenção. Também é relevante inserir nesse debate o papel da transparência pública e do controle social.

Como limitações da pesquisa, cabe destacar o espaço temporal de dez anos tomado como ponto de partida, caso ocorra a ampliação desse corte podem ser encontrados resultados diferentes. O trabalho também utilizou um protocolo próprio para a revisão sistemática, assim, outros protocolos, por considerarem critérios diferentes para a filtragem de artigos, podem apresentar resultados diversos. Para pesquisas futuras, sugere-se uma investigação do conteúdo teórico que vem sendo abordado pela produção científica nacional, a introdução de novas bases de consulta, bem como a elaboração de pesquisas que verifiquem como a área da administração pública, em particular, está abordando essa temática.

\section{REFERÊNCIAS}

ABRAMO, C. W. Percepções pantanosas: a dificuldade de medir a corrupção. Novos Estudos CEBRAP, (73), 33-37, 2005.

ABRUCIO, F. L. Trajetória recente da gestão pública brasileira: um balanço crítico e a renovação da agenda de reformas. Rev. Adm. Pública [online]. Vol.41, n.spe, pp.67-86, 2017. ISSN 0034-7612 
ANDERSSON, S. Beyond Unidimensional Measurement of Corruption. Public Integrity, 19, 58-76, 2017. doi: 10.1080/10999922.2016.1200408

ARANHA, A. L. M. A Rede Brasileira de Instituições de Accountability: Um Mapa Do Enfrentamento da Corrupção Na Esfera Local." Tese (Doutorado). Universidade Federal de Minas Gerais - UFMG, 2015.

AVRITZER, L.; FILGUEIRAS, F. Corrupção e controles democráticos no Brasil. Brasília, DF: CEPAL. Escritório no Brasil/IPEA. (Textos para Discussão CEPAL-IPEA, 32). 40p, 2011.

AVRITZER, L.et al. (Org.). Corrupção: ensaios e críticas. Belo Horizonte: UFMG, 2008.

BECKER, G. Crime and punishment: an economic approach. Journal of Political conomy. Vol. 76, pp. 175-209, 1968.

BOTELHO, L. L. R., DE ALMEIDA CUNHA, C. C.; MACEDO, M. O método da revisão integrativa nos estudos organizacionais. Gestão e sociedade, 5(11), 121-136, 2011.

BUENO, R. L. P.; BRELÀZ, G.; SALINAS, N. S. C. Administração Pública Brasileira no Século 21: Seis Grandes Desafios. Revista do Serviço Público, v. 67, n. Ed. Especial, p. 728, 2016.

CALDAS, M. P.; TINOCO, T. Pesquisa em Gestão de Recursos Humanos nos Anos 1990: um estudo bibliométrico. RAE. V. 44. Nº 03, 2004.

CARVALHO, J. M. de. Quem transgride o quê? In: CARDOSO, Fernando H.; MOREIRA, Marcílio M. (Coord.). Cultura das transgressões no Brasil: lições da história. 2. ed. São Paulo: Saraiva, 2008. p. 69-94.

COOK, D. J.; MULROW, C. D.; HAYNES, R. B. Systematic reviews: synthesis of best evidence for clinical decisions. Annals of Internal Medicine, v. 126, n. 5, p. 376-380, 197.

EHRLICH, I. Participation in Illegitimate Activities: An Economic Analisys. In: BECKER, Gary S.; LANDES, William M. (ed.). Essays in the economics of crime and punishment. Columbia University Press. Nova Iorque, 1974.

FERRAZ, C.; FINAN, F. Exposing corrupt policiticans: the effects of Brazil's publicily released audits on electoral outcomes. Quarterly Journal of Economics, v.123, n.2, p. 703$745,2008$.

FILGUEIRAS, F. A tolerância à corrupção no Brasil: uma antinomia entre normas morais e prática social. Opinião Pública, v. 15, n. 2, p. 386-421, 2009.

FILGUEIRAS, F. Corrupção, democracia e legitimidade. Belo Horizonte: UFMG, 2008a. 
FILGUEIRAS, F. Marcos teóricos da corrupção. In: AVRITZER, Leonardo et al. (Org.). Corrupção: ensaios e críticas. Belo Horizonte: UFMG, 2008b. p. 353-361.

GREENHALGH, T. Papers that summarize other papers (systematic review and meta analyses). British Medical Journal, London, v. 315, n. 7109, p. 672-675, Sep, 1997.

JAIN, A. K. Corruption: a review. Journal of Economics Surveys, v. 15, n. 1, 2001.

KAUFMANN, D; KRAAY, A.; MASTRUZZI, M. Governance Matters III: Governance Indicators for 1996-2002 (Policy Research Working Paper Series 3106). Washington, DC: World Bank, 2002.

KLITGAARD, R. Controlling Corruption. Berkeley: University of California Press, 1988.

LOIOLA, E.; BASTOS, A. V. B. A produção acadêmica sobre Aprendizagem Organizacional no Brasil. RAC, v. 7, n. 3, jul./set.181-201, 2003.

MARANI, S. C. Z.; BRITO, M. J.; SOUZA, G. C.; BRITO, V. G. P. Os Sentidos da Pesquisa sobre Corrupção. Revista de Administração Pública, 52(4), 712-730, 2018. doi:

10.1590/0034-7612175197

MARTINS, D. G. O estado da arte da capacidade institucional: uma revisão sistemática da literatura em língua portuguesa. Cadernos EBAPE. BR, 19(1), 165-189, 2021.

MAURO, P. Corruption and Growth. Quarterly Journal of Economics, v. 110, n. 3, p. 681$712,1995$.

O‘DONNELL, G. Accountability horizontal e novas poliaquias. Lua Nova, São Paulo, v. 44, p. 27-54, 1998.

PETERSON, J.; PEARCE, P. F.; FERGUSON, L. A.; LANGFORD, C. A. Understanding scoping reviews: definition, purpose, and process. Journal of the American Association of Nurse Practitioners, 29(1), 12-16, 2017.

PINHO, J. A. G. de. Reforma do aparelho do Estado: Limites do gerencialismo frente ao patrimonialismo. Revista Organizações \& Sociedade. Salvador, n. 12, p. 59. 1998.

PINHO, J. A. G.; SACRAMENTO, A. R. S. O Círculo Vicioso da Corrupção no Brasil: Limites Estruturais e Perspectivas de Rompimento. Revista do Serviço Público, v. 69, n. Espec., p. 181-209, 2018.

ROSE-ACKERMAN, S. Corruption and government: causes, consequences, and reform. Cambridge: Cambridge University Press, 1999. 
SACRAMENTO, A. R. S. Organizações da sociedade civil que atuam no combate à corrupção no Brasil. 2010.

SACRAMENTO, A. R. S.; PINHO, J. A. G. A produção acadêmica brasileira sobre corrupção em administração pública: um estudo no período compreendido entre 1997 e 2008. In: EnAnpad, 33., 2009, São Paulo. Anais. São Paulo: Anpad, 2009.

SHLEIFER, A.; VISHNY, R. Corruption. Quarterly Journal of Economics, v. 108, p. 599617, 1993.

SOUZA, F. J. B.; SILVA, S. A. M.; GOMES, A. O. Corrupção no Setor Público:

Considerações a Partir da Literatura Internacional. In: XLI Encontro da Associação Nacional de Pós-Graduação e Pesquisa em Administração (EnANPAD), São Paulo, Anais... São Paulo: Anpad, 2017.

SOUZA, F. J. B.; SILVA, S. A. M.; GOMES, A. O. Corrupção no Setor Público: Agenda de Pesquisa e Principais Debates a Partir da Literatura Internacional. Administração Pública e Gestão Social, v. 11, n. 3, p. 1-18, 2019.

SPECK, B. W. Mensurando a Corrupção: uma revisão de dados provenientes de pesquisas empíricas. In: HOFMEISTER, W. (Org.). Os Custos da Corrupção. São Paulo: Fundação Konrad Adenauer, 2000. p. 9-45.

TANZI, V. Corruption Around The World. IMF Staff Papers, v. 45, dec/1998.

VOSGERAU, D. S. A. R.; ROMANOWSKI, J. P. Estudos de revisão: implicações conceituais e metodológicas. Revista diálogo educacional, 14(41), 165-189, 2014. 